The nine radiocarbon dates contain some minor inconsistencies, but taken as a whole they justify the conclusion of the authors that the time covered by the four building periods is from about 800 to 400 B.C. This is an important new piece of evidence to add to that which has been accumulating in recent years for the existence of elaborate ceremonial structures in the first millenium B.c., that is to say before the Classic Period in the first millenium A.D. to which belong the famous ceremonial centres of the lowland Maya and those at Teotihuacan and Monte Alban.
Both stages imply the disposal of much labour by a ruling class, witness the carriage of 1,000 tons of stone for more than $60 \mathrm{~km}$. without wheeled transport or pack animals, for a single ritual deposit at La Venta. The chief difference seems to be that clay rather than stone and lime plaster was used for constructional purposes in the pre-Classic sites. The report also gives powerful support to those who believe the Olmec to have preceded the lowland Maya and other high cultures of this part of the American continent.

G. H. S. Bushnelt

\title{
MISTLETOE IN AUSTRALIA
}

$\mathrm{M}$ ISTLETOE has never been a serious pest in Britain. The Australian species, however, are different and cause extensive losses (C.S.I.R.O., Rural Res., 29 ; 1959). They do not even find a use as Christmas decoration. Only in Tasmania is the parasite not a problem, but why this is so when it occurs widely on the mainland is not known. In the other States, and especially in New South Wales and Queensland, mistletoe damage is so extensive and so costly that it constitutes a problem of national importance.

Areas may be found in which practically every tree has been parasitized. Many of them die, and those that do not produce less timber. One worker has estimated that when 38 per cent of the crown of the host tree has been displaced by mistletoe, wood production is down as much as 55 per cent.

The widespread, outright killing of trees in water catchment areas has led to soil erosion, silting, and higher flood-levels in wet seasons. In agxiculture, mistletoe is a nuisance, as it often kills shade trees.

Forestry departments have found that the incidence of mistletoe attack has been increasing over recent years. For example, records maintained by the Commonwealth Forestry and Timber Bureau on a number of small plots at Kowen show that between 1952 and 1955 the infestation increased from 75 to 79 per cent a year.

Eradication based on amputation of infested branches or felling badly infested trees is much too expensive for large-scale operations. Certain sprays are efficient killers; but it is often difficult to reach all the mistletoe on an affected tree with spray equipment. Biological control methods, using insects or pathogens, hold little hope of success. In 1937, the Forestry Department of Queensland found that possums had a decided liking for mistletoe and apparently preferred it to almost any other type of food. It is possible that before the coming of the white man, these and other leaf-eating animals exerted a strong control on mistletoe. It is impracticable under present conditions to restore the possum population to its former level. Clearing for settlement, resulting in more light and greater numbers of birds around the trees, has probably increased the spread of mistletoe : it seems to grow best where the light is good, and birds are the chief means of spreading the seeds, which stick to their beaks or pass through with their droppings.

Chemicals seemed to offer the only effective means of control, and, in 1948, Mr. G. C. Greenham, of the Commonwealth Scientific and Industrial Research
Organization Division of Plant Industry, began experiments to see whether it would be possible and practical to control the parasite by a selective poison injected into the trunk of the host tree. The work has entailed exhaustive trial and error because of the close physiological association between the host and parasite - a poison that would kill the mistletoe might also be expected to kill or at least seriously damage the tree.

The first poison tried was the selective phytocide, copper sulphate. This gave fair results, but was not good enough, because usually it did not kill more than half the mistletoe. The next step in the investigation was to obtain information about the way in which substances are moved or translocated throughout a tree. This was done by using radioactive isotopes. Supplies of radioactive iron, cobalt and zinc salts were used in the first botanical experiment with radioactive isotopes in Australia.

The third step was to try out the hormone selective weed-killers. So far, about a dozen of these have been checked; the triethanolamine salt of $2,4-D$ was found to be outstanding in that it killed or seriously injured a high proportion of the mistletoe without harming the host eucalyptus.

Other hormone-type compounds and mixtures of them are being tested, and some, including various forms of $2,4-D$, hold considerable promise. The hydrazine salt of $2,4-D$ is being exhaustively tested at present because preliminary trials have shown it to be at least as good as the triethanolamine salt and to have a faster effect.

Mistletoe dies up to two years after the tree has been injected, and the final assessment of the effectiveness of the treatment should be postponed until at least two years have elapsed. Mistletoe surviving after this time may be subjected to the treatment again without harming the host tree, which does not become sensitized to 2,4-D as a result of earlier dosing. Nor does the mistletoe become resistant, and the second treatment will kill about 50 per cent of the remaining parasites. Because of the high rate of re-infestation in some areas, it would be unrealistic to aim at complete eradication. Since the first treatment may be expected to kill 70-90 per cent of the parasites, it is more practical to re-treat the trees every five years.

Information is now available concerning the effect of the treatment on eight species of eucalyptus. Reasonably good results have been obtained for seven of the eight species, and this suggests that the treatment may be suitable for destroying inistletoc on a wide range of eucalyptus hosts. 